\title{
Modelling, Implementation and Application of a Flexible Manufacturing Cell
}

\author{
F. Leighton, R. Osorio, G. Lefranc
}

\author{
Felipe Leigthon \\ Universidad de Las Américas \\ Vina del Mar - Chile \\ E-mail: felipe.leigthon@gmail.com \\ Román Osorio \\ Universidad Nacional Autónoma de México \\ Instituto IIMAS \\ E-mail: roman@servidor.unam.mx \\ Gastón Lefranc \\ Pontificia Universidad Católica de Valparaíso \\ Escuela de Ingeniería Eléctrica, Valparaiso - Chile \\ E-mail: glefranc@ucv.cl
}

\begin{abstract}
This paper presents Petri Nets Model, the implementation and application of a Assembly Flexible Cell. The Cell is composed by a robotic manipulator, a computer vision system and a conveyor. The system is applied to assembly several products, showing only two of them.
\end{abstract}

Keywords: Flexible Manufacturing Cells, Assembly, CIM, Petri Nets.

\section{Introduction}

Within the area of the manufacturing, CIM model (Computer Integrated Manufacturing) permits the automation all the activities in a manufacturing company: the organization, storage (ASRS), manufacturing (CAM), engineering (CAE) and Quality Control. These activities are supported by local area networks and related database. In CAM includes fabrication, assembly and quality control of products, utilizing robotics manipulators, computer vision, etc., to facilitate automation [1]. These industrial systems, allow flexible their production and to automate their processes, without human intervention.

Assembly systems are widely used in several industries. These systems are composed by robotics manipulators, computer vision and sensors to complete the production task accurately. However, since these systems are composed of many components, it is difficult to deal with unexpected situations. For example, an undetected error may propagate and end up as a detectable failure which may cause the whole line to stop its operation. In this case, it may take considerable time to diagnose the system and identify the main reasons for the failure. There exist approaches to detect and to predict failures, but the usage of these approaches is limited. [2], [3]

The ability to produce a variety of products through the combination of modular components is a meaningful benefit of product modularity. There are five different ways that modular products are developed in industry. Component-swapping modularity can be achieved when two or more alternative types of components are paired with the same basic product body to create different product variants. This modularity is often associated with the creation of product variety as perceived by the customer. [6]

The Assembled Flexible Cell is part of a developed Flexible System in the Laboratory of Robotics, Artificial intelligence and Advanced Automation Lab, in the Escuela de Ingeniería Eléctrica de la Pontificia Universidad Católica de Valparaíso, Chile. FMS system includes: an 
ASRS cell (Automatic Storage Retrieval System) [4], with an executive system and database [5], Servoing Systems [7], [9] and Stereo computer vision [8], [10], [11] and Flexible Manufacturing cell. [12]

In this paper is presented an assembly cell modeled by Petri nets, the implementation and the application to the assembly of some products, in a manufacturing flexible cell. The Assembly Flexible Cell is composed by a robotic manipulator, a computer vision system and a conveyor.

\section{Structure of the Assembly Cell}

The assembled flexible cell of is constituted by a robotic arm, a system of vision and an system of automated transport. The system robotic manipulator used is IBM 7547 type Scara; the computer vision system is an stereo vision (two webcams); and the automated system of transport, is conformed by four conveyor belts that form a "circuit" around the robotic manipulator and the assembled area. It function is to interconnect the different cells from the system, like the ASRS (storage), the assembly flexible cell, manufacturing flexible cell and the flexible cell of quality control. This conforms a Flexible system of Manufacture, as it is seen in the (Fig.1). Through this system of transport are transferred pallets with different kits to assembly. In (Fig.2), is the transfer.

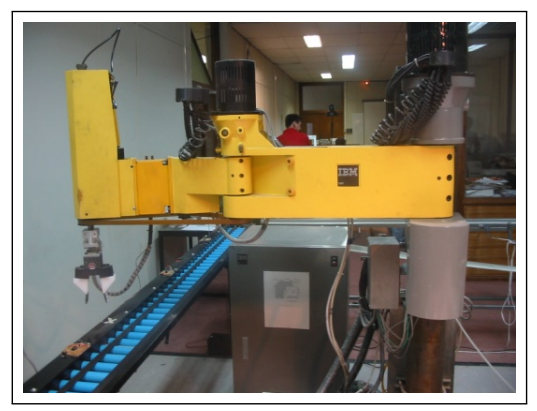

Figure 1: The Flexible Manufacturing System

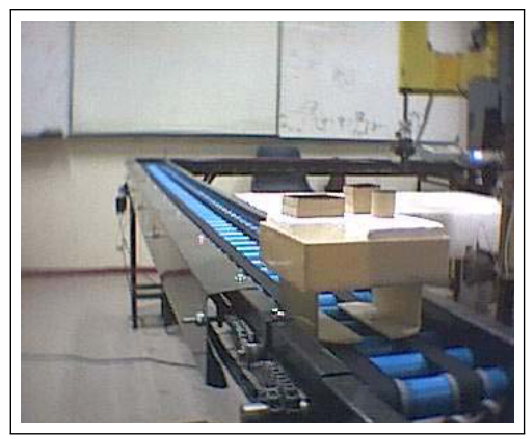

Figure 2: Pallets with kit in the conveyor belt

The stereo vision system, (Fig.3), determines what pieces are in pallet, and the pallet position of the in the work area to make the assemly. In order to prove the cell a wood figure is assembled (geometric figure), and then making assembly of a electrical interrupt and electrical plug, common in houses and offices. The robotics manipulator takes the pieces inside the pallet and make the assembly programmed, The vision system contributes to the determination of the position and direction of the parts to be assembled. 

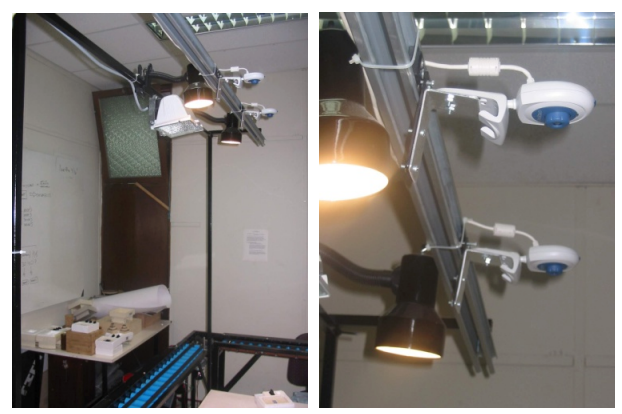

Figure 3: The system of Vision

\section{Aplications of Flexible Assembly Cell.}

The applications of the cell are to assemble geometric figure (Fig.4a), to test if the system works. Then, making assembly of a electrical interrupt and electrical plug with one, two or three plug per unit (Fig.4b).
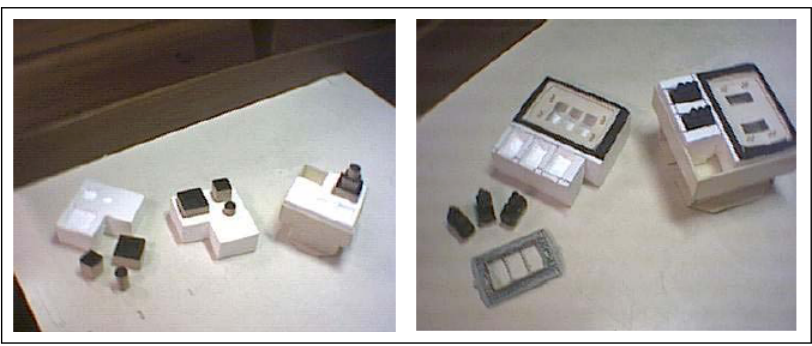

Figure 4: a) Kit of wood parts. b) Kit of plugs.

\section{Computer Vision System.}

The vision system have to determine the space position of pallets and objects within the space of work of the robotic manipulator. The Stereo Vision has to be able of visualizing objects of different size, send the order to manipulator to pick up the pallets and put in the working area, recognize the oarts inside the pallets and then send the order to manipulator to assemble the product in other pallet. Finally, the vision system verify is the product is well/assembled, giving the orders to manipulator to transport the pallet with assembled product ro the conveyor.

The images are captured by two webcam cameras. These images pass through a process of digitalization during which is made a discretización of the space coordinates of the image $(x, y)$ denominated sampling of the image, and a discretización of the amplitude of the intensity of light in each point or pixel of the image, which denominates quantification of the gray level (Fig.5). The system make image segmentation, separating the different objects and applying a threshold based on the histogram (Fig.6).

Then, the center of mass or centroide of an object of a binary image is computed (Fig.7).

The direction of an object determines by the minus existing distance between its center of mass and an element of his contour. Therefore, the first step to follow to calculate the direction of an object is to determine which are píxeles that they belong to his contour. For doing this, a gradient of the image is used. So that an object is taken, the effector of the manipulator must be oriented of such way that their direction is perpendicular to the direction of the straight line 


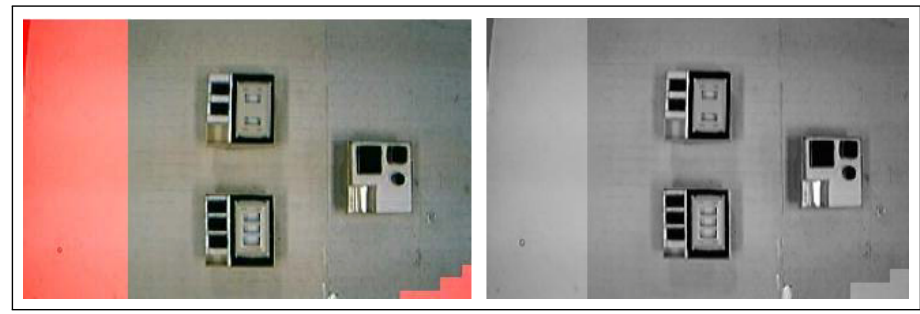

Figure 5: Digital image

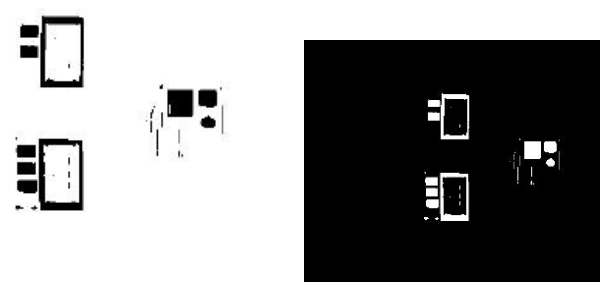

Figure 6: Segmentation and Thresholding

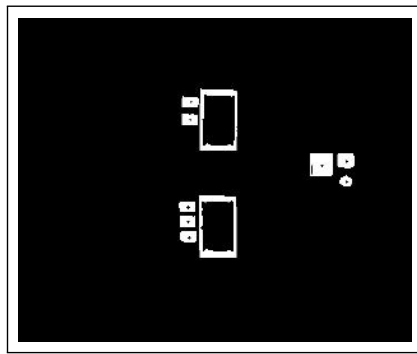

Figure 7: Centroide of the objects

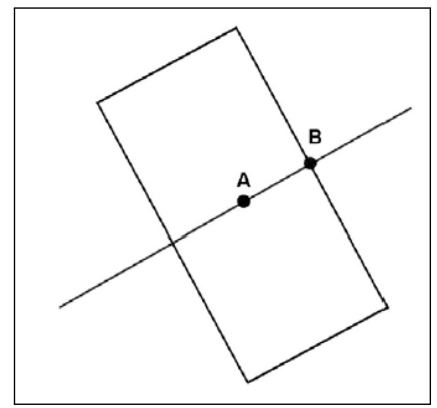

Figure 8: Direction of the object

that constitutes the minimum range between the center of mass of the object and its contour. This can be observed in following (Fig.8), where the point A corresponds to the center of mass of the rectangle and point $\mathrm{B}$ is determined finding the minimum range between the centroide and the contour of the object. The union of these points forms a perpendicular straight line to the direction that must have the effector of the manipulator to pick up the object. 


\section{Petri Nets Model of the Assembly Cell.}

Assembly systems has many components and it is difficult to deal with unexpectes situations. Error non detected could propagate and to produce failure in the system, causing stop in the operation of the line. It takes time to diagnose, and to identify the reasons of the failure. A Petri Net Model (PN) of the Flexible Assembly Cell permits a simulation of the behaviour of the Assembly Cell, detecting failure nd an evaluation of the performance. The (Fig.9) shows the definitions of places and transitions and the (Fig.10), PN Model.

\begin{tabular}{|c|c|c|c|}
\hline Places & Table 3: Place definition & $\mathrm{Tr}$ & Table 4: Transitions definition \\
\hline & Arrive assembly order to cell & T0 & MR moves to CT \\
\hline $\mathrm{P}_{1}$ & Pallet in ASRS to CT & $\mathrm{Tl}$ & Move pallet from ASRS to CT \\
\hline $\mathrm{P}_{2}$ & Pallet in conveyor CT & $\mathrm{T} 2$ & CT transports pallet to assembly place \\
\hline $\mathrm{P}_{3}$ & MR in initial position & $\mathrm{T3}$ & MR pick pallet \\
\hline $\mathrm{P}_{4}$ & Pallet in place to be pick by MR over CT & T4 & MR place pallet in workspace and open effector \\
\hline $\mathrm{P}_{\mathrm{s}}$ & MR with pallet & T5 & MRup $20 \mathrm{~cm}$ \\
\hline $\mathrm{P}_{6}$ & Pallet in workspace & T6 & RM moves pallet to assembly zone \\
\hline $\mathrm{P}_{7}$ & MR over pallet & T7 & RM moves out \\
\hline $\mathrm{P}_{\mathrm{B}}$ & MR at $20 \mathrm{~cm}$ from workspace & T8 & SV3D captures scene \\
\hline $\mathrm{P}_{0}$ & Pallet in right position & T9 & SV3D processes scene \\
\hline $\mathrm{P}_{10}$ & SV3D has digital image & $\mathrm{T} 10$ & SV3D send to MR, position and or ientation of Objl \\
\hline $\mathrm{P}_{11}$ & SV3D has position and orientation of objects & T11 & MR pick Obj 1 from pallet that is in workspace \\
\hline $\mathrm{P}_{12}$ & MR has position and orientation of $\mathrm{Obj} \mathrm{l}$ & T12 & MR moves obj 1 to assembly zone and returnto $20 \mathrm{~cm}$ \\
\hline $\mathrm{P}_{13}$ & MR has obj 1 & $\mathrm{~T} 13$ & SV3D send to MR, position and orientation of Obj 2 \\
\hline $\mathrm{P}_{14}$ & Obj 1 in workspace & T14 & MR pick Obj 2 \\
\hline $\mathrm{P} 15$ & MR has position and orientation obj 2 & $\mathrm{~T} 15$ & MR moves obj 2 to assembly zone \\
\hline $\mathrm{P} 16$ & MR has obj 2 & $\mathrm{~T} 16$ & MR pushes forassembly \\
\hline $\mathrm{P} 17$ & MR placed obj 2 over obj 1 in workspace & T17 & MR places obj 2 and return to $20 \mathrm{~cm}$ from workspace \\
\hline $\mathrm{P} 18$ & Obj 2 assembled with obj 1 & $\mathrm{~T} 18$ & SV3D send to MR, position and orientation of Obj 3 \\
\hline P19 & MR at $20 \mathrm{~cm}$ from workspace & T19 & MR pick Obj 3 \\
\hline $\mathrm{P} 20$ & MR has position and orientation obj 3 & $\mathrm{~T} 20$ & MR moves obj 3 to assembly zone \\
\hline $\mathrm{P} 21$ & MR has obj 3 & $T 21$ & MR places obj 3 and return to $20 \mathrm{~cm}$ from workspace \\
\hline $\mathrm{P} 22$ & MR placed obj 3 over obj $1-2$ in workspace & T22 & SV3D send to MR, position and orientation of $\mathrm{Obj} 4$ \\
\hline P23 & Obj 3 assembled over obj $1-2$ & T23 & MR pick Obj 4 \\
\hline P24 & MR has position and orientation obj 4 & $\mathrm{~T} 24$ & MR moves obj 4 to assembly zone \\
\hline $\mathrm{P} 25$ & MR has obj 4 & T25 & MR pushes for assembly and pick PE to pallet \\
\hline $\mathrm{P} 26$ & MR placed obj 4 over obj $1-2$ in workspace & T26 & MR place PE and pick pallet \\
\hline P27 & MR has $\mathrm{PE}$ in the pallet & $\mathrm{T} 27$ & MR moves pallet and place in CT \\
\hline P28 & MR has the Pallet & $T 28$ & CT transport pallet to ASRS \\
\hline P29 & Pallet in CT & T29 & Pallet is place in ASRS \\
\hline $\mathrm{P3} 30$ & Pallet in ASRS & $\mathrm{T} 30$ & MR moves to initial position \\
\hline
\end{tabular}

Figure 9: Place and Transition definitions for PN Model

Definitions:

MR - Robotics Manipulator;

$\mathrm{CT}$ - Conveyor;

SV3D - Stereo Vision Systems;

Obj 2 - Internal Cover;

Obj 4 - Plug 2;
ASRS: Automatic Storage and Retrieval System

RM - Mobile Robot

Obk 1 - Cover of the product

Obj 3 - Plug 1

$\mathrm{PE}$ - Final assembly product

\section{Evaluations of the Flexible Assembly Cell.}

For the evaluations of the project different tests were made. One of them is to measure the time taken to make an assembly. Table 1 shows the times of joint, like for the evaluations, the iterations, with and without retiring pallet from the circuit of conveyor belts.

Table 1. Time to assembly a product 


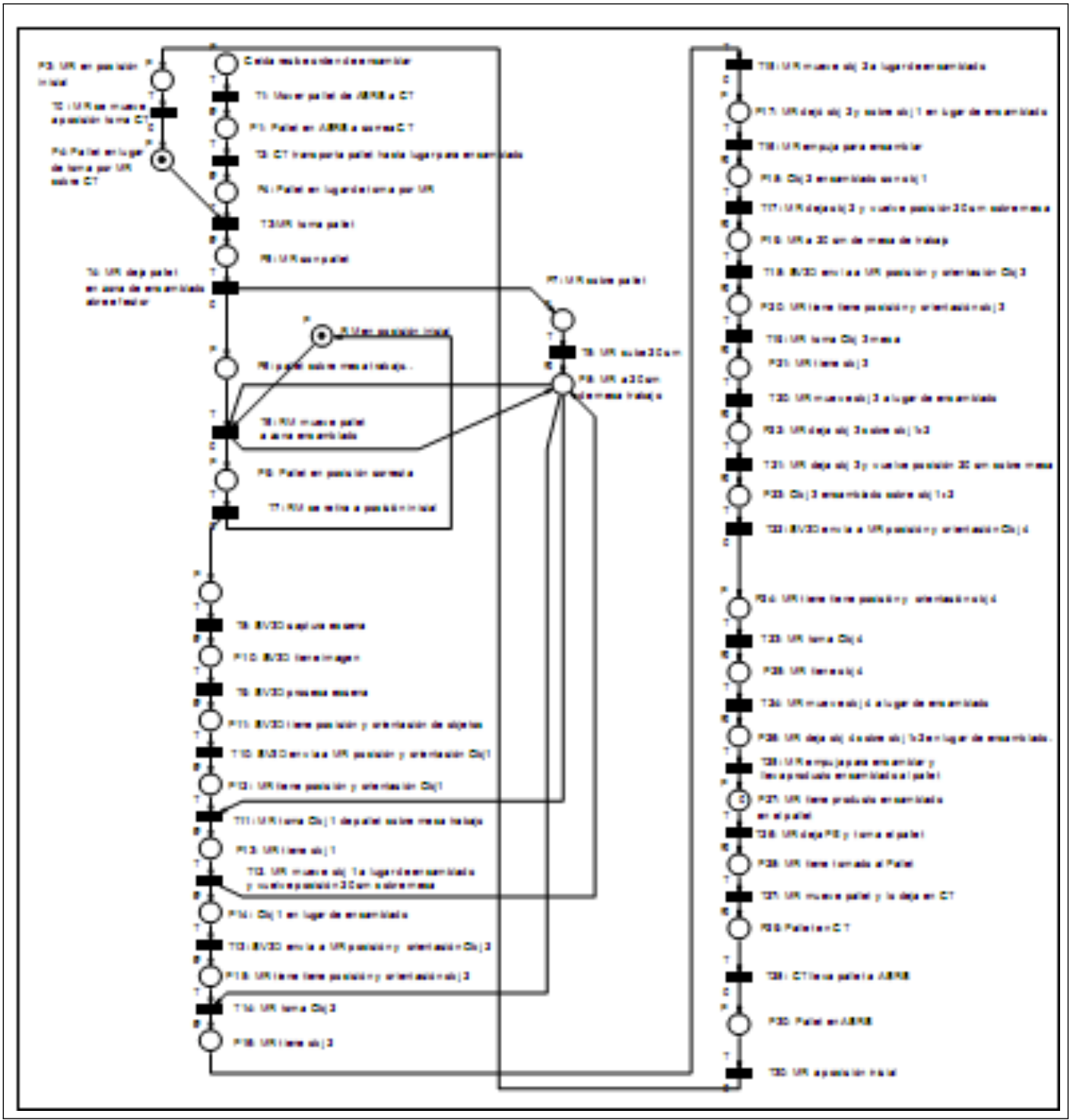

Figure 10: Flexible Assembly Cell PN Model

\begin{tabular}{|c|c|c|c|c|c|c|c|}
\hline Geometric figures & & Simple plug & & Doble plug & & Triple plug & \\
\hline $\begin{array}{c}\text { with } \\
\text { retiring }\end{array}$ & $\begin{array}{l}\text { without } \\
\text { retiring }\end{array}$ & $\begin{array}{l}\text { with } \\
\text { retiring }\end{array}$ & $\begin{array}{l}\text { without } \\
\text { retiring }\end{array}$ & $\begin{array}{l}\text { with } \\
\text { retiring }\end{array}$ & $\begin{array}{l}\text { without } \\
\text { retiring }\end{array}$ & $\begin{array}{l}\text { with } \\
\text { retiring }\end{array}$ & $\begin{array}{l}\text { without } \\
\text { retiring }\end{array}$ \\
\hline 1'4"' & 1'37' & 1'12"' & 1'34" & $1^{\prime} 25^{\prime \prime}$ & 1'59"' & 1'45"' & 2'22"' \\
\hline
\end{tabular}

The time of assembled goes from 1 minute 12 seconds to 2'22", that is to say, the time when the manipulator puts the pallets in the work area, until the manipulator pick up the pallet with the assembled product.

A bad position of the pallets in the work area produces that the manipulator do not pick up the pallets or it pick up bad. One of the problem is the illumination affecting the quantification of the objects, like in the determination of the centroide and the direction of each one of the subparts. The Stero Vision System send to Manipulator wrong position. This problem it solves, in part, with the installation of a system of illumination superior to the existing one. A small mobile robots is used to move the pallet to the right place, using two walls to put the pallet in 
the desired position, the best place for stereo vision system (Fig.11). It can see the mobile robot, the walls and the pallet in the workspace. This tobots receives order from the computer cell.

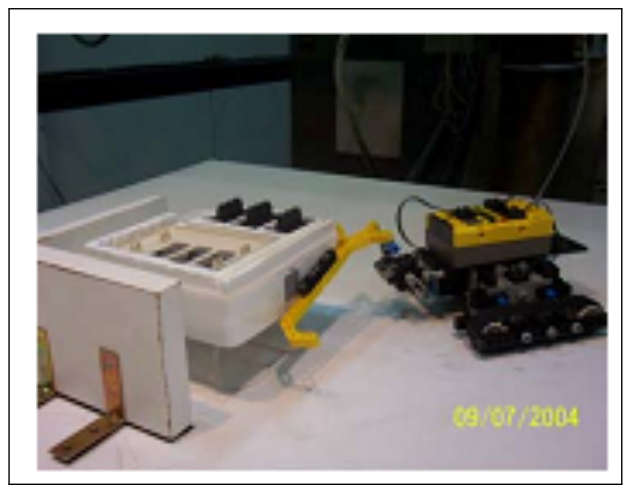

Figure 11: Mobile Robot and the two walls.

Other evaluation is the measurement of the percentage of correct assembly. It is made ten measurement, for different assembled such as for the geometric figure, and each type of plug. Each one considers iterations with retiring pallet from the "circuit", and without retiring from them. The results given by Table 2, reflecting the percentage of error by amount of products, in other words, if the product to assemble has 3 pieces (geometric figure, simple plug) and fail in one, the result is $33 \%$ of error, or, if it has of 5 pieces, and it fails in two, have an error of the $40 \%$, ( triple plug).

Table 2. Percentage of Faults to assembly a Product

\begin{tabular}{|c|c|c|c|c|c|c|c|c|}
\hline & Geometric figures & & Simple plug & & Doble plug & & Triple plug & \\
\hline $\begin{array}{c}\text { with } \\
\text { retiring }\end{array}$ & $\begin{array}{c}\text { without } \\
\text { retiring }\end{array}$ & $\begin{array}{c}\text { with } \\
\text { retiring }\end{array}$ & $\begin{array}{c}\text { without } \\
\text { retiring }\end{array}$ & $\begin{array}{c}\text { with } \\
\text { retiring }\end{array}$ & $\begin{array}{c}\text { without } \\
\text { retiring }\end{array}$ & $\begin{array}{c}\text { with } \\
\text { retiring }\end{array}$ & $\begin{array}{c}\text { without } \\
\text { retiring }\end{array}$ \\
\hline 1 & $0 \%$ & $0 \%$ & $0 \%$ & $0 \%$ & $50 \%$ & $0 \%$ & $20 \%$ & $20 \%$ \\
\hline 2 & $33 \%$ & $0 \%$ & $33 \%$ & $0 \%$ & $0 \%$ & $25 \%$ & $0 \%$ & $20 \%$ \\
\hline 3 & $0 \%$ & $33 \%$ & $33 \%$ & $0 \%$ & $25 \%$ & $0 \%$ & $40 \%$ & $0 \%$ \\
\hline 4 & $33 \%$ & $0 \%$ & $33 \%$ & $0 \%$ & $0 \%$ & $25 \%$ & $0 \%$ & $0 \%$ \\
\hline 5 & $0 \%$ & $0 \%$ & $0 \%$ & $0 \%$ & $25 \%$ & $0 \%$ & $60 \%$ & $0 \%$ \\
\hline 6 & $33 \%$ & $0 \%$ & $33 \%$ & $33 \%$ & $25 \%$ & $0 \%$ & $0 \%$ & $40 \%$ \\
\hline 7 & $0 \%$ & $0 \%$ & $0 \%$ & $33 \%$ & $0 \%$ & $0 \%$ & $20 \%$ & $40 \%$ \\
\hline 8 & $33 \%$ & $33 \%$ & $33 \%$ & $0 \%$ & $25 \%$ & $50 \%$ & $0 \%$ & $60 \%$ \\
\hline 9 & $33 \%$ & $0 \%$ & $0 \%$ & $33 \%$ & $25 \%$ & $50 \%$ & $20 \%$ & $20 \%$ \\
\hline 10 & $0 \%$ & $0 \%$ & $0 \%$ & $0 \%$ & $0 \%$ & $0 \%$ & $60 \%$ & $20 \%$ \\
\hline
\end{tabular}

\section{Conclusions}

In this paper has been presented a Petri Nets Model, the implementation and the of a Assembly Flexible Cell. The system assemblies several products, only is presented a wood assembly and assembly of different kind of electrical interrupt and electrical plugs. The Cell is composed by a robotic manipulator, a computer vision system and a conveyor. Different effectors for the robotics manipulator are designed for different kind of product to assembly, considering different factors of the object.

The Flexible Assembly Cell is modelled and simulated using Petri nets. This model and the simulation permit to evaluate the performance of the Cell, and correct it before starting a new assembly. 
The real cell is tested assembled geometric objects and electrical interrupt and plugs. The time of assembled goes from 1 minute 12 seconds to 2'22', that is to say, the time when the manipulator puts the pallets in the work area, until the manipulator pick up the pallet with the assembled product.

The Stereo Vision System recognizes the objects whithin the working area, establishing the position of the pallets and the objects in the pallets. Problems affects the quatification determination of the centroid and direction of each object, producing error from $33 \%$ to $59 \%$. The problem is solved with changing illumination and adding a small mobile robot to move the pallet to the desired position.

\section{Bibliography}

[1] Lefranc, G., La Manufactura Integrada por Computador: un Tutorial, Magazine Automática e Innovación de la Asociación Chilena de Control Automático, vol 1, 2, 1993, pg 45.

[2] T. C. Cao, A.C., Sanderson, 1992, Sensor-based error recovery for robotic task sequences using fuzzy petri-nets, Proceedings of the 1992 IEEE International Conference on Robotics and Automation, Vol.2, pp.1063-1069.

[3] Q. Jing, W. Xisen, P. Zhihua, X. Youngcheng, 1996, A Research on Fault Diagnostic Expert System Basedon Fuzzy Petri Nets for FMS Machining Cell, Proceedings of IEEE International Conference on Industrial Technology, pp. 122-125.

[4] Andrada I., Lefranc G. Sistema Experimental de un sistema de almacenamiento automatizado. I Parte. XV Congreso de la Asociación Chilena de Control Automático 2002.

[5] Maizares M., Lefranc G., Base de datos y programa ejecutivo para un sistema AS/SR. IEEE Latin-American Conference on Robotics and Automation. Chile, 2003.

[6] Lefranc, Gastón, Simulación de la generación de secuencias de ensamblado en una celda flexible de producción. Automática e Innovación de la Asociación Chilena de Control Automatico. Ano 3. Volumen 2. Nº7, 1996.

[7] Lefranc G., Cano F., Sistema Servoing Pick and Place, Congreso Latinoamericano de Control Automático, 2003, Guadalajara, México.

[8] Schleyer G., Lefranc G., Experimental 3-D Visual servoing for FMS applications. Third IFAC IEEE Conference on Management of Control of Production and Logistics MCPL'2004.

[9] Opazo M., Lefranc G., Visual Servoing. Fourth IFAC IEEE Conference on Management of Control of Production and Logistics, MCPL 2007.

[10] Schleyer G., Lefranc G., Tridimensional Visual Servoing, Studies In Informatics and Control, Volume 18 . Issue 3 . 2009.

[11] Schleyer G., Lefranc G., Color Images Segmentation using SplitËMerge and Region Growing Techniques in RGB and HSV Color Spaces, International Jornal of Computers, Communications \& Control, Vol. V Issue 1, 2010.

[12] Leighton F., Lefranc G., Flexible Assembly Cell using Scara Manipulator. Third IFAC IEEE Conference on Management of Control of Production and Logistics MCPL'2004. 